\title{
English for Teaching and Learning of Science and Mathematics in Malaysian Schools: A Comparative Study on Perception between Different Ethnics
}

\author{
Mohd Arip Kasmo ${ }^{1}$, Abur Hamdi Usman ${ }^{2}$, Fazilah Idris ${ }^{1}$, Mohamad Mohsin Mohamad Said ${ }^{1}$, Nor Afian Yusof ${ }^{1}$, \\ Hamdzun Haron ${ }^{1} \&$ Azizi Umar ${ }^{1}$ \\ ${ }^{1}$ Centre for Liberal Studies, The National University of Malaysia, Malaysia \\ ${ }^{2}$ Institute of Islam Hadhari, The National University of Malaysia, Malaysia \\ Correspondence: Abur Hamdi Usman, Institute of Islam Hadhari, The National University of Malaysia, 43600 \\ Bangi, Selangor, Malaysia. Tel: 60-166-905-082. E-mail: aburhamdiusman@yahoo.com
}

\author{
Received: December 3, 2014 Accepted: January 7, 2015 Online Published: April 28, 2015 \\ doi:10.5539/ies.v8n5p111 URL: http://dx.doi.org/10.5539/ies.v8n5p111
}

\begin{abstract}
This paper reports a study on the perception of the people toward the teaching and learning of Science and Mathematics using English. Altogether, 641 respondents obtained randomly from all over Malaysia participated in the study. The respondents, male and female from the age of 20 to 55 were given a set of questionnaire, containing statements on various issues of Science and Mathematics. Each statement is accompanied with five choices of responses in the form of Likert type scale ranging from 1. Strongly disagree, 2. Disagree, 3. Not sure, 4. Agree, and 5. Strongly agree. One of the statement of the questionnaire analysed was "It is easier to learn science and mathematics in English". The raw data was analysed using the Statistical Package for the Social Sciences (SPSS) and also ANOVA. The result of the study shows that $45.7 \%$ of the respondents rejected the statement, $24.4 \%$ accepted the statement and $29.3 \%$ were not sure. There is significant difference of means between the respondents with academic background in science compared to respondents with non-science academic background.
\end{abstract}

Keywords: English, teaching, learning, science, mathematics, comparative, perception

\section{Introduction}

English was introduced for the teaching and learning of Science and Mathematics in Malaysian government school in 2003 (Cheng et al., 2007). The decision to switch from Malay to English as the medium of instruction in the teaching and learning of science and mathematics was made by the then Prime Minister of Malaysia Dr. Mahathir Muhammad, who announced a RM 5 billion allocation to implement the teaching of Science and Mathematics from year 2003 to year 2008 (Lumumba, 2004). The implementation of English for the teaching of Science was supported by the urban elites, but majority of the people were against it (Benson \& Kosonen, 2013).

The majority of the people who opposed the teaching of Science and Mathematics have their own arguments against it. For example, one of the arguments of those who opposed the teaching and learning of Science and Mathematics using English reiterated that it was a blow to the sanctity of the Malay language (Wee, 2010). Supporters of the new policy of teaching and learning Science and Mathematics using English raised the importance of English as an international language, and there was growing pressure everywhere to use international languages for scientific subjects (Spolsky, 2009). Although the issue of teaching and learning of Science and Mathematics had died down when the teaching and learning of Science and Mathematics was switched back to the Malay language, the study was informed about the people's perception of the policy. Although there are already many studies on the issue, this study specifically touches on the perception of the people in general and is not focused only on the teachers or students.

\section{Literature Review}

The decision to teach Science and Mathematics using English in the government schools was made in order to improve the ability of the students to communicate in English (Tong, 2014). One of the reasons why English was introduced for teaching and learning of Science and Mathematics is related closely to the idea of globalisation of 
the information and communication technology where English is used widely (Vaish, 2010). The figure who made the decision to switch the teaching and learning of Science and Mathematics to English is none other than the former Prime Minister of Malaysia, Mahathir Muhammad who realised that the achievement of science and technology in Malaysia had slowed down due to poor English (Braine, 2010).

The implementation of English for the teaching of Science and Mathematics in Malaysian schools was supported by some and opposed by others. Substantial majority of teachers from all language groups did not agree with English as the language of instruction and $95 \%$ of the total samples of teachers in a study were "very unhappy" and "unhappy" when they were asked what they felt about the language of instruction for Science and Mathematics in English (Marcinkowski, 2012). However the environment for learning and the teaching English in the Malaysian schools and the higher education institutions was not conducive for communication English, and hence the students were unable to communicate in English well (Baldauf et al., 2013).

The number of negative reaction toward the teaching of Science and Mathematics in English outnumbered the positive reaction by a factor of nearly 4 to 1 . The unpopularity of English for teaching Science and Mathematics among teachers and the students may have caused a deleterious consequence to the students and is reflected in the achievement of the students in a few states including Perlis, Kelantan, Sabah and Sarawak where students who failed in Science and Mathematics have exceeded 50\% (Kirkpatrick \& Sussex, 2012).

The teaching of Science and Mathematics in English was opposed by those who wanted the teaching to be reverted to Malay, also by those who wanted the teaching and learning to be in their mother tongue. The Chinese community wanted the teaching of Science and Mathematics in the Chinese school to be in Chinese language and the Indian community wanted the teaching of science and mathematics in the Tamil school to be in Tamil language. The Chinese education lobbies claimed that the teaching of Science and Mathematics was a serious threat to the existence of mother-tongue education system (Banks, 2009).

On the other hand, teaching Science and Mathematics in Malay language has also some drawbacks. The Malay language which was used as the medium of the teaching of Science and Mathematics before the decision to use English in 2003 lacked the terms which are used in science and technology. The government agency which was entrusted with the task of preparing new terms for science and technology has created many terms which are almost entirely absorbed from English words by merely altering the spelling of the words to suit the Malay language. For example, oxygen was changed to oksigen, hydrogen to hidrogen, oxide to oksida, carbon dioxide to karbon dioksida (Tham, 1990).

These are basic terms which are commonly used in science and are easy to be used. However more complex words which are commonly used in science and technology cannot be easily changed into the Malay language by changing the spelling, without losing the original meaning. In Physics for example, the thermodynamic law is changed to hukum thermo dinamik and many others. In Biology for example, the word mitosis and meiosis undergo no changes in spelling; thus, they are left are they are in English.

The same problem is present in other non-European languages. Absorption of other scientific terminologies into another language is not alien to science. For example, the Arabic word alkuhl was changed to alcohol, alqali to alkali (Katamba, 2005). Students who are educated in English language face little problem in understanding the scientific and technological terms, while those who have no English language background, using the scientific and technology terms which have been changed to Malay language will surely face some problems in understanding the terms. Therefore, it is easier to use the original English terms in science which supports the reason for using English language in Science and Mathematics.

One of the reasons which was raised was regarding the sources of scientific knowledge which are mainly available in English. This is worsened by the fact that researchers from local universities and research institution are often encouraged to publish in English to gain international recognition. A lot of references such as books, journals, newsletters and millions of web pages are available in English. This has made the government realize that English is indispensable for transferring scientific knowledge especially in engineering and medical fields (Tong, 2014).

\section{Method of the Study}

The study was conducted with 641 respondents obtained randomly throughout the country of Malaysia. Respondents that comprise male and female from different education backgrounds and age group were given booklets of questionnaire, which contain statements relating to the issues of science and technology. Each statement has five choices of responses, known as Likert scale ranging from 1. (Strongly disagree), 2. (Agree), 3. (Not sure), 4. (Agree), and 5. (Strongly agree). Likert scale is used in this study because it measures attitude of 
the respondents.

Kothari (2011) listed five reasons why Likert scale is a good instrument of choice. Firstly, Likert scale is relatively easy to construct. Second, it is liable instrument because respondents will have to answer each statement in the instrument. Third, each statement included in the Likert scale is given an empirical test for discriminating ability. Fourth, Likert scale can easily be used. Fifth, it requires less time to construct a Likert scale instrument.

In this study the respondents were given 30 minutes to respond to the questionnaire, and the booklets were collected to be analysed using the Statistical Package for the Social Sciences (SPSS) in order to obtain the mean and percentage of responses. The mean difference was also tested using t-test for independent samples and also using one-way ANOVA. The means, percentages, t-test result as well as the one-way ANOVA test are presented in the form of tables and diagrams in this study. The results of the analysis are interpreted and discussed at the last part of this paper. The findings of the study can be used by the relevant authority to map further steps to be taken in using English as the medium of instruction for Science and Mathematics.

\subsection{Data Analysis}

Data was analysed to obtain the mean response for the item, "It is easier to study Science and Mathematics in English". The mean of response is shown in Table 1.

Table 1. The mean response for all the respondents

\begin{tabular}{cccccc}
\hline & $\mathrm{N}$ & Minimum & Maximum & Mean & Std. Deviation \\
\hline \multirow{2}{*}{ Valid N } & 638 & 1.00 & 5.00 & 3.2900 & 1.14241 \\
\hline
\end{tabular}

Table 1 shows that the mean response for the statement is 3.2900. The mean response lies between 3 (not sure) and 4 (agree which indicates that the respondents were not sure whether to accept or reject the statement. The next analysis is to find the percentage of responses for all the respondents. The percentage of the responses is shown in Table 2.

Table 2. The percentages of the responses for all the respondents

\begin{tabular}{|c|c|c|c|c|}
\hline & Frequency & Percent & Valid Percent & $\begin{array}{l}\text { Cumulative } \\
\text { Percent }\end{array}$ \\
\hline \multicolumn{2}{|c|}{ Strongly disagree 47} & 3.6 & 7.4 & 7.4 \\
\hline Disagree & 111 & 8.6 & 17.4 & 24.8 \\
\hline Not sure & 187 & 14.5 & 29.3 & 54.1 \\
\hline Agree & 193 & 15.0 & 30.3 & 84.3 \\
\hline Strongly agree & 98 & 7.6 & 15.4 & 99.7 \\
\hline
\end{tabular}

Table 2 shows that $7.4 \%$ of the respondents strongly disagreed with the statement, $17.4 \%$ disagreed, $29.3 \%$ were not sure, $30.3 \%$ agreed and $15.4 \%$ expressed strongly agreement with the statement. This means that the number of respondents who claimed that it is easier to learn Science and Mathematics in English is 45.7\%. Therefore, less than half of the number of respondents support the teaching of Science and Mathematics in English, 29.3\% were undecided and $24.8 \%$ did not accept that it is easier to learn Science and Mathematics in English. Hence, the percentage of responses is presented in the form of bar chart as shown in Diagram 1. 


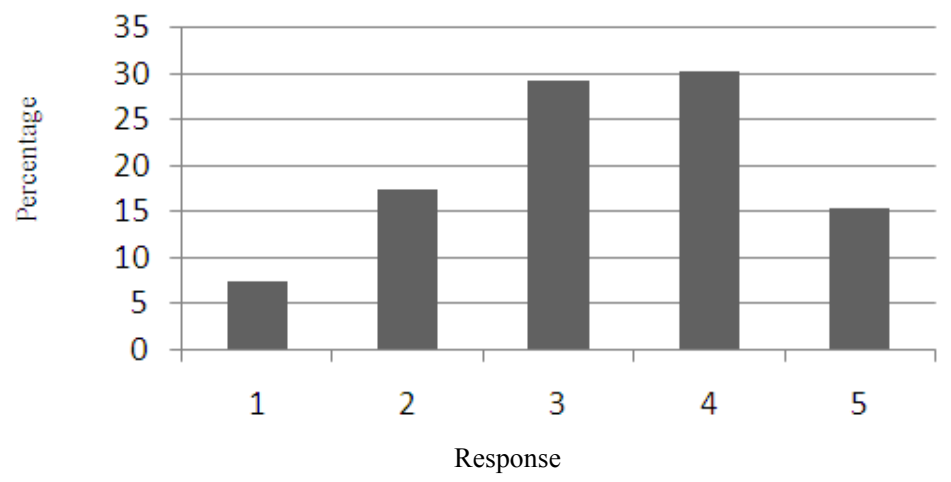

Diagram 1. The percentages of the responses

Diagram 1 shows that the biggest percentage is response number4 which is $30.3 \%$, followed by response 3 (not sure), response 2 (disagree), response 5 (strongly agree) and response 1 (strongly disagree). The next analysis is to find the mean response according to the academic background of the respondents. The mean response for the respondents based on academic background is shown in Table 3 .

Table 3. The mean response for the respondents based on academic background

\begin{tabular}{lccc}
\hline Academic background & Mean & $\mathrm{N}$ & Std. Deviation \\
\hline Science & 3.5245 & 347 & 1.09458 \\
Non-Science & 3.0104 & 288 & 1.13385 \\
\hline
\end{tabular}

Table 3 shows that the mean for the respondents who have the academic background in Science is 3.5245 while those with non-science academic background is 3.0104. The mean responses show that respondents with scientific academic background show stronger level of acceptance than respondents with non-science academic background.. The difference of mean was analysed using t-test to see if the difference of means is significant. The result of the analysis is shown in Table 4.

Table 4. The t-test between the mean responses of the respondents according to the academic background

\begin{tabular}{lccccc}
\hline & $\mathrm{F}$ & Sig. & $\mathrm{t}$ & $\mathrm{df}$ & Sig. (2-tailed) \\
\hline Equal variances assumed & 1.425 & .233 & 5.797 & 633 & .000 \\
Equal variances not assumed & & & 5.778 & 603.294 & .000 \\
\hline
\end{tabular}

Table 4 shows that the $\mathrm{p}$ value is 0.000 , and the value is smaller than the critical value 0.05 . Therefore, the $t$-test shows that there is a significant difference between the mean of the respondents whose academic background is in science compared to those respondents whose academic background is not in science. In addition, the next analysis aims to find the mean response according to the gender of the respondents. The result of the analysis is shown in Table 5.

Table 5. The mean response according to the gender of the respondents

\begin{tabular}{llll}
\hline Gender & Mean & $\mathrm{N}$ & Std. Deviation \\
\hline Male & 3.4075 & 292 & 1.15247 \\
Female & 3.1908 & 346 & 1.12599 \\
\hline
\end{tabular}


Table 5 shows that the mean response of the male respondents is 3.4075 and the mean response for the female is 3.1908. The mean shows that level of acceptance among male respondents is stronger than the female for the item, "It is easier to learn science in English". However, the difference of mean seems to be small. In order to know whether the mean difference is significant or not, t-test was carried out on the means response. The result of the t-test is shown in Table 6.

Table 6. The t-test result of the difference of mean based on the gender

\begin{tabular}{lccccc}
\hline & $\mathrm{F}$ & $\mathrm{Sig}$. & $\mathrm{t}$ & $\mathrm{df}$ & Sig. (2-tailed) \\
\hline Equal variances assumed & .339 & .561 & 2.397 & 636 & .017 \\
Equal variances not assumed & & & 2.392 & 613.098 & .017 \\
\hline
\end{tabular}

Table 6 shows that the $\mathrm{p}$ value is 0.017 which is smaller than the critical value of 0.05 . This indicates that the difference of mean between the responses of the respondents based on gender is significant. Furthermore, the next analysis was carried out to obtain the mean value according to age of the respondents, and the result of the analysis is shown in Table 7.

Table 7. The means of responses according to the age groups

\begin{tabular}{llll}
\hline Age group & Mean & $\mathrm{N}$ & Std. Deviation \\
\hline $20-30$ & 3.3555 & 467 & 1.11274 \\
$31-55$ & 3.1377 & 138 & 1.25094 \\
$>55$ & 2.9643 & 28 & 1.07090 \\
\hline Total & 3.2907 & 633 & 1.14634 \\
\hline
\end{tabular}

Table 7 shows the mean responses of the respondents based on their age group. The mean response for the age group between 20 to 30 years old is 3.3555 , between the age of 31 to 55 is 3.1377 and the mean response of the age above 55 years old is 2.9643 . The mean seems to indicate that the acceptance of the statement that "It is easier to study Science in English" decreases with age. The mean responses are plotted to form a line graph as shown in Diagram 2.

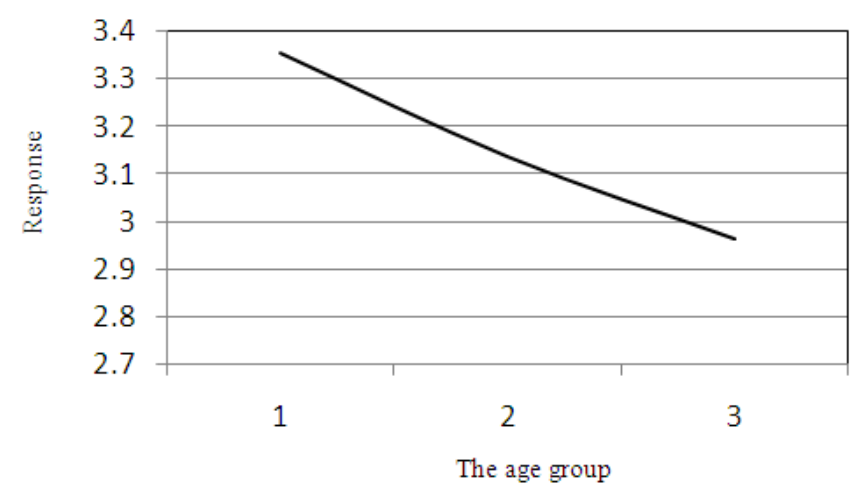

Diagram 2. The line graph for the mean responses according to the age group

Diagram 2 shows the mean responses to the level of acceptance to the statement "It is easier to learn Science and Mathematics using English". Furthermore, the next analysis is to know the mean responses according to the ethnic background of the respondents. The result of the analysis is shown in Table 8. 
Table 8 . The mean response according to ethnic background of the respondents

\begin{tabular}{llll}
\hline & Mean & $\mathrm{N}$ & Std. Deviation \\
\hline Malay & 3.3141 & 433 & 2.34387 \\
Chinese & 3.5868 & 121 & 1.20187 \\
Indian & 3.5179 & 56 & 1.11177 \\
\hline
\end{tabular}

Table 8 shows that mean response of the respondents based on their ethnic groups. The response of Malay respondents is 3.3141, Chinese is 3.5868 and Indian is 3.5179. There seems to be a difference of means between the respondents of different ethnic. In addition, the mean difference is tested to see the significant difference using one-way ANOVA. The result of the test is shown in Table 9.

Table 9. One-way ANOVA test between the means of the respondents according to ethnic

\begin{tabular}{llllll}
\hline & Sum of Squares & df & Mean Square & F & Sig. \\
\hline Between Groups & 20.511 & 5 & 4.102 & 3.197 & .007 \\
Within Groups & 810.845 & 632 & 1.283 & & \\
\hline
\end{tabular}

Table 9 shows the $p$ value is 0.007 , and the value is smaller than the critical value of 0.05 . Hence, the difference between the mean responses of the respondents based on their ethnic is significant.

The next analysis seeks to find the percentage of each response according to respondents' ethnic background. The results of the analysis are shown in Table 10.

Table 10. The percentage of the response of the respondents based on ethnic background

\begin{tabular}{lcccccc}
\hline & \multicolumn{2}{c}{ Malay } & \multicolumn{2}{c}{ Chinese } & \multicolumn{2}{c}{ Indian } \\
\hline Strongly agree & 35 & 8.1 & 9 & 7.4 & 2 & 3.6 \\
Agree & 82 & 19.0 & 13 & 10.7 & 10 & 17.9 \\
Not sure & 141 & 32.6 & 29 & 24.0 & 12 & 21.3 \\
agree & 122 & 28.2 & 38 & 31.4 & 21 & 37.5 \\
Disagree & 53 & 12.2 & 32 & 26.4 & 11 & 19.6 \\
\hline & 433 & 100 & 121 & 100 & 56 & 100 \\
\hline
\end{tabular}

Table 10 shows the percentages of the responses according to ethnic groups. Taking into consideration that strongly agree and agree imply accepting the statement, the percentage of Malay respondents who accepted the statement is $40.4 \%$, the percentage of the Chinese respondents who accepted the statement is $57.4 \%$ and the percentage of the Indian respondents is $57.6 \%$. Considering the response strongly disagree and disagree as rejection of the statement, $27.1 \%$ of the Malay respondents, $18.1 \%$ of the Chinese respondents and $21.5 \%$ of the Indian respondents rejected the statement. In this context all indicators pointed out that the Malay respondents are most reluctant to accept the statement "It is easier to learn Science and Mathematic in English". Thus, to illustrate the result of the analysis clearer, the percentages of the responses of the respondents according to the ethnics are plotted onto a line graph as shown in Diagram 3. 


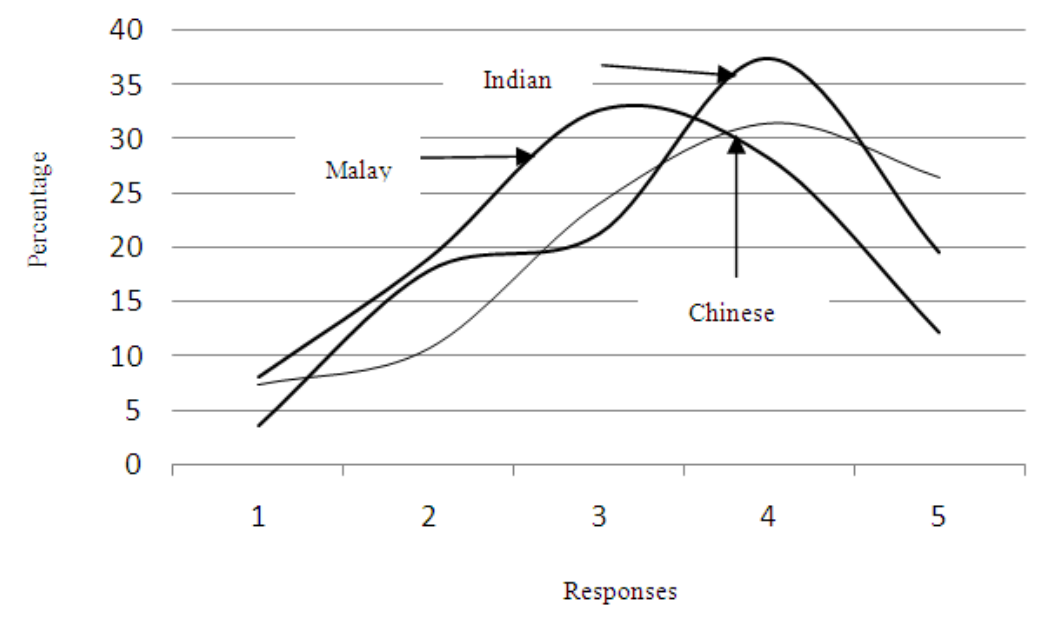

Diagram 3. The percentage line graph of the responses according to the ethnic

\section{Discussion}

The results of the study show that less than fifty percent of the respondents accepted the statement that it is easier to learn Science and Mathematics in English (see Table 2). The rest of the respondents rejected the statement or were not sure about it. This finding reflects findings from earlier studies conducted by other researchers.

Furthermore, the level of acceptance was also not strong because the mean response is 3.2900. Even it is brought to the closest round number, the mean is 3 which is neutral. So in general, it can be concluded that Malaysians are neutral in the issue of the teaching and learning Science and Mathematics in English (see Table 1).

Analysis of means for the respondents based on gender shows that there are difference of means between male and female respondents with male expressing stronger acceptance for the item stating that it is easier to learn Science and Mathematics using English than the female counter part. The difference of mean is also significant (see Tables 5 and 6). This means that the Science students accepted the statements that it is easier to learn Science and Mathematics in English.

The study also found out that the acceptance to the statement, "It is easier to learn Science and mathematics in English" became weaker with age (see Table 7), and this finding confirms what has been pointed by Baker (2011) who says that it is easier to learn a language when young. All the results do not indicate strong acceptance or rejection of the statement, and the difference of mean response between male and female respondents as well as the difference of mean between the Science and non-science students shows significant difference. The mean response of the respondents based on their ethnic groups show that the Chinese respondents' mean response is 3.5868 and the mean response of the Indian respondents is 3.5179 (see Table 8). If both mean responses are rounded, both of the mean responses of the Indian and Chinese become 4. (Agree). Hence, the Chinese and the Indian accept the statement that it is easier to learn Science and Mathematics in English.

In a study been conducted to find the English proficiency among Malaysian students, Canagarajah (2005) discovered that the Chinese and the Indian are better than the Malays. Further, Hamzah (2010) explained that the Malays, majority of whom live in rural are lagging behind compared to their urban counter parts in mastering the English language because they are left with inexperienced English teachers.

\section{References}

Baker, C. (2011). Foundations of Bilingual Education and Bilingualism (5th ed.). Canada: Multilangual Matters.

Baldauf, R. et al. (2013). Language Planning in Primary Schools in Asia. UK: Routledge.

Banks, J. A. (2009). The Routledge International Companion to Multicultural Education. New York: Routledge.

Benson, C., \& Kosonen, K. (2013). Education: Inclusive Teaching and Learning in Non-Dominant Languages and Cultures. Netherland: Springer Science \& Business Media.

Braine, G. (2010). Non-native Speaker English Teachers: Research, Pedagogy, and Professional Growth. New York: Routledge.

Canagarajah, A. S. (2005). Reclaiming the Local in Language Policy and Practice. New Jersey: Routledge. 
Cheng, Y. C. et al. (2007). Reform of Teacher Education in the Asia-Pacific in the New Millennium: Trends and Challenges. New York: Springer Science \&Business Media.

Hamzah, A. (2010). The Challenges Will Learners and Teachers In Malaysia Face In Learning and Teaching ESL/EFL. Germany: Grin Verlag.

Katamba, F. (2005). English Words: Structure, History, Usage. New York: Routledge.

Kirkpatrick, A., \& Sussex, R. (2012). English as an International Language in Asia: Implications for Language Education. New York: Springer Science and Business. http://dx.doi.org/10.1007/978-94-007-4578-0

Kothari, C. R. (2011). Research Methodology: Methods and Techniques. New Delhi: New Age International.

Lumumba, N. T. A. (2004). Cyberspace, Distance Learning, and Higher Education in Developing Countries: Old and Emergent Issues Of Access, Pedagogy, and Knowledge Production. Leiden, Netherland: BRILL.

Marcinkowski, C. et al. (2012). Malaysia and the European Union: Perspectives for the Twenty-First Century. Hamburg: Lit Verlag.

Spolsky, B. (2009). Language Management. Cambridge: Cambridge University Press. http://dx.doi.org/10.1017/CBO9780511626470

Tham, S. C. (1990). A Study of the Evolution of the Malay Language: Social Change and Cognitive Development. Singapore: NUS Press.

Tong, J. (2014). Education Dilemma in Malaysia: Past, Present and Future. Singapore: Partridge Publishing.

Vaish, V. (2010). Globalization of Language and Culture in Asia: The Impact of Globalization Processes on Language. A \& B Black.

Wee, L. (2010). Language without Rights. Oxford: Oxford University Press. http://dx.doi.org/10.1093/acprof:oso/9780199737437.001.0001

\section{Copyrights}

Copyright for this article is retained by the author(s), with first publication rights granted to the journal.

This is an open-access article distributed under the terms and conditions of the Creative Commons Attribution license (http://creativecommons.org/licenses/by/3.0/). 